\title{
Psychosocial Interventions and the Demoralisation of Humanitarianism
}

Vanessa Pupavac

School of Politics and International Relations

University of Nottingham

Nottingham NG7 2RD

vanessa.pupavac@ nottingham.ac.uk

Summary: This paper critically analyses from a political sociology standpoint the international conceptualization of war-affected populations as traumatized and in need of therapeutic interventions. It argues for the importance of looking beyond the epidemiological literature to understand trauma responses globally. The paper explores how the imperative for international psychosocial programmes lies in developments within donor countries and debates in their humanitarian sectors over the efficacy of traditional aid responses. The aim of the paper is threefold. First, it discusses the emotional norms of donor states, highlighting the psychologising of social issues and the cultural expectations of individual vulnerability. Second it examines the demoralization of humanitarianism in the 1990s and how this facilitated the rise of international psychosocial work and the psychologising of war. Third, it draws attention to the limitations of a mental health model in Croatia, a country which has been receptive to international psychosocial programmes. Finally it concludes that the prevalent trauma approaches may inhibit recovery and argues for the need to re-moralize resilience. Please note this is not a final proofed version.

A final proofed version of this paper was published under the following reference:

Vanessa Pupavac (2004) 'Psychosocial Interventions and the Demoralisation of Humanitarianism.' Journal of Biosocial Science, Vol. 36 pp. 491-504. Special issue on Mental Well-being in Complex Emergencies edited by Astier Almedom at Tufts University.

\section{Introduction}

War-affected populations have been conceptualised under international policy of the last decade as traumatised en masse and in need of therapeutic interventions (de Jong et al, 2000; Mollica, 2000). The paper critically analyses the evidence from an ethics-political scientific standpoint and affirms the importance of looking beyond the epidemiological literature to understand trauma responses globally (Bracken, 2002). Humanitarian action is not apolitical (Macrae, 2001; de Waal, 1997), nor is international psychosocial work as a branch of humanitarianism. The nature of humanitarian aid proffered to recipient populations is bound up with the relationship of international non-governmental organisations, predominantly Western, to their own societies and governments. The imperative for international psychosocial programmes lies in developments within donor countries and debates in their humanitarian sectors over the efficacy of traditional aid responses. The decade of the 1990s witnessed the politicisation and militarisation of aid as instruments of conflict management. The Balkans region in particular became subject to the new aid strategies and is therefore interesting to discuss in relation to the impact of 
the new approaches. The aim of the paper is threefold. First, the paper discusses the emotionology of donor states, that is the emotional norms of donor states, highlighting the psychologising of social issues and the cultural expectations of individual vulnerability. Second the paper examines the demoralisation of humanitarianism in the 1990s and how this facilitated the rise of international psychosocial work and the psychologising of war. Third the paper draws attention to the limitations of a mental health model in Croatia, a country which has been receptive to international psychosocial programmes. Finally it is concluded that the prevalent trauma approaches may inhibit recovery and argues for the need to re-moralise resilience.

\section{Western emotionology}

Contemporary culture in donor countries takes the self and the self's subjective feelings as the moral touchstone. Subjective feelings have become the main reference point in the post-traditional societies of the West which lack strong shared ideological, moral or religious convictions and collective consciousness (Nolan, 1998). As a consequence, social issues are increasingly approached through the prism of the emotions, while emotional pleading is becoming the dominant form of public engagement (ibid.). Cultural preoccupation with feelings does not imply that emotions are stronger: passion has arguably declined with the loss of conviction. Rather social norms have shifted from emotional reticence to emotional display. At the same time, the erosion of external references and communal affiliations has not unleashed a vigorous individualism, but has left an anxious, insecure self: a 'minimal self' (Lasch, 1984). 'Modern society plunges us into a condition of uncertainty in which we often lose track of what we feel and slip into states of depression and helplessness', argues an advocate of mass therapeutic programmes for the public (Samuels, 2001, p. 3).

Firm convictions, whether religious, moral or political, promote resilience of character. In distinction, the personality type of contemporary Western culture, bereft of convictions and disposed to introspection, is characterised by emotional vulnerability. This sense of vulnerability is exemplified in the dramatic rise of post-traumatic stress disorder (PTSD) in the West. The PTSD classification has been persuasively analysed as the archetypal syndrome of the vulnerable self of post-traditional societies (Bracken, 2002; Young, 1995). Individuals today already have a fragile sense of purpose in their lives and are vulnerable to anything that disturbs the precarious coherence they have achieved. The characteristic intrusive-avoidance symptoms of PTSD are related to the shattering of meaning and attempts to integrate distressful experiences and regain a sense of coherence (ibid.). In other words, PTSD as 'a disorder in which the victim experiences a profound sense of meaninglessness and dislocation' is an exaggerated form of the pervasive cultural anxiety over meaningfulness and personal identity (Bracken, 2002, p. 187). Indeed people appear to seek meaning in the diagnosis of PTSD as a disorder that encapsulates the contemporary human condition (Furedi, 2002b; Nolan, 1998, pp. 9-17). Feelings of anxiety and vulnerability have led to an explosion of psychological complaints and demands for professional diagnosis and support. A substantial proportion of visits to the doctor in Britain now relate to issues concerning emotional well-being (Shaw and Middleton, 2001). Therapy resonates with the hyper-reflexive subjectivity of contemporary society, fostering enormous growth in the numbers of counselling 
professionals. The creation of a huge counselling industry has been further promoted by state policy, which is developing therapeutic approaches to address social issues from crime, educational achievement, family breakdown, poverty to social exclusion (Nolan, 1997). Increasingly social transformation is being displaced to the sphere of the emotions and interpersonal communication.

Over the last decade policy-makers have found a new source of legitimisation affirming the self and managing the population's emotions (Furedi, 2002b; Nolan, 1998). These therapeutic interventions are given momentum with the advocacy of emotional selfunderstanding and well-being as fostering good citizens and good employees (Giddens, 1994; Samuels, 2001). The emotionology of state policy also parallels new Western management techniques which emphasise transferable 'soft' skills to facilitate communication and team co-operation to enhance responses in rapidly changing markets (Sennett, 1998). Such instrumentalisation of the emotions has been condemned as the 'Mcdonaldization of the emotions', in which emotional responses become mechanised: 'petrified, routinized, and otherwise made artificial' (Mestrovic, 1997, p. 146). There are potentially alienating and coercive aspects of contemporary Western emotionology with the reinterpretation of social problems in terms of emotional functionalism/dysfunctionalism. Preoccupation with emotional functionality is problematising individuals' emotional responses and their ability to cope with life events. So even where individuals do not specifically seek support, professionals are encouraged to intervene proactively with therapeutic programmes.

The provision of counselling has become a routine feature of contemporary culture and may be experienced as an education into vulnerability. After every disaster, teams of trauma counsellors descend on the area in question, offering PTSD counselling, not just to bereaved relations, but to the whole community. Policy is premised on the assumption of vulnerability. Indeed there are few trauma studies which take a salutogenic approach, that is, focus on those who are resilient (Waysman et al, 2001) and it is neglected in emergency responses (see Almedom in this volume). This is not surprising given our cultural disposition to look for vulnerability. The present expectation of vulnerability may be compared to the Aberfan disaster of 1966 in which 116 children and 28 adults were killed as a result of a landslide onto a school in Wales. No counselling was offered to the bereaved relations, while the surviving children were quickly returned to schooling after a fortnight so that they would not dwell on the tragedy (Furedi, 2002a, p. 230). The villagers were praised by the Times newspaper as having done 'admirably in rehabilitating themselves with very little help' (Times quoted in ibid.).

Today, in sharp contrast, expectations of those at risk of emotional trauma have to include anybody who witnesses distressful events on television. Thus it has been claimed that individuals can develop 'varying degrees of PTSD from graphic displays of carnage' (Coward, 2001). Following this view, proposals were made or discussed to offer counselling over the Iraq War to students from Arizona State University in the United States to Stirling University in Scotland. Whether such proposals were dismissed or not, the very suggestion that students whose only exposure to the war was likely to be through 
the media might be in need of counselling illustrates cultural expectations of vulnerability and how the categories of those who are deemed at risk of incapacity are expanding.

The very report of a community having experienced conflict is sufficient for international humanitarian agencies to deem the group as having PTSD and requiring specific psychosocial support. The automatic provision of mass trauma counselling in the wake of any disaster exemplifies the cultural projection of individuals as universally vulnerable and in need of emotional processing to mediate psychosocial dysfunctionality. Essentially the international psychosocial model may be represented as below:

experience of distressful event $\rightarrow$ trauma responses $\rightarrow$ psychosocial dysfunctionality

The model assumes that people globally understand their suffering through the prism of psychology and that their suffering may be addressed through therapeutic programmes (Bracken, 2002; Summerfield, 2001; Young, 1995). However, if PTSD is understood as a disorder of meaning (Bracken, 2002), this suggests both the culturally specific appeal of PTSD counselling and its limitations in addressing a wider social crisis of meaning.

The model overlooks how distress is mediated by political or religious convictions, cultural beliefs, social circumstances, previous experience of adversity and not simply the distressing events themselves (Shepherd, 2000). Irrespective of whether populations appear resilient, they are deemed to be suffering from 'hidden scars', 'invisible wounds' or 'undiagnosed trauma' and requiring preventive treatment to break cycles of emotional dysfunctionalism (Mollica, 2000). Their resilience is effectively pathologised as a failure to process emotions. For the model conflates the experience of distress with emotional dysfunctionality requiring therapeutic management (de Jong et al, 2000). Consequently, while cultural differences are acknowledged, it is only in so far as entailing the adaptation of therapeutic methods. The overall prescription of people as vulnerable and needing to process their emotions remains in international responses.

What is at issue is not simply the relevance of the PTSD model globally and what sort of emotional management is or is not culturally appropriate, but its problematising of communal responses and communal resilience. There is growing realisation that current therapeutic approaches may inhibit community recovery, firstly by denying resilience and validating vulnerability, and secondly by interfering with communities' own resources (Rose et al, 2003). The professionalisation of emotional responses may unintentionally weaken communal responses, by encouraging identification with and dependence on (international) professionals. However, even where community cohesion is regarded as weak prior to the particular disaster, the very experience of disaster may pull a community together (Rogers, 1993). Nevertheless, the therapeutic norms of donor countries continue to be projected onto disaster-affected populations globally and influence international humanitarian responses.

The pervasiveness of therapeutic responses has led social commentators to characterise contemporary Western society as a 'post-traumatic culture' (Farrell, 1998). Tellingly, therapeutic forms rather than religious ceremonies are becoming the predominant cultural 
rites that accompany public and private events. The counselling profession has been described as 'a new priestly class' displacing religious leaders as the guardians of society (Nolan, 1998). The idea of the therapeutic ethos as a new religious creed captures well how cultural expectations of emotional vulnerability have become prescriptive. It seems individuals have to reveal emotional vulnerability to authenticate the suffering they have witnessed and their compassion for the victims. The demise of the traditional British stiff upper lip was evidenced in the displays of mass grief following Diana's death. Nobody, it seems, is exempt from the dictates of contemporary therapeutic norms, including the British royal family, who was widely accused of being unfeeling for not being demonstrative over Diana's death. In the same vein, the former BBC journalist Kate Adie was attacked for her emotionally cold reporting of the Dunblane school massacre in 1996 (Mayes, 2000). Under the therapeutic ethos, not to be traumatised in the face of tragic events is tantamount to being callous and indifferent to human suffering. This helps to explain the phenomenon of 'survivors' guilt' and the relatively high instance of secondary trauma among emergency workers or other staff involved in the care of victims. Indeed secondary stress disorder has been explained by the Dart Center for Journalism and Trauma as an 'empathic response that affects people such as therapists and journalists when they become overwhelmed by others' traumatic experiences' (http://www.dartcenter.org/selfstudy/index.html). Through displaying emotional vulnerability and requiring therapy, carers demonstrate their empathy. Failing to acknowledge emotional vulnerability and seek therapy is almost becoming regarded as socially irresponsible. To suggest that the stiff upper lip is more useful than counselling and that counselling is unhelpful or even that time heals is to invite a tirade of outraged responses, as the Oxford-based Cochrane Centre (Joseph, 2003) or the British agony aunt Virginia Ironside have found.

\section{De-moralisation of humanitarianism}

Alongside the cultural developments within donor countries, which encouraged the rise of international therapeutic interventions, there were important developments within the aid sector, which facilitated the adoption of psychosocial programmes. In Vaux (2001), former Oxfam representative, describes humanitarian work as being underpinned by emotion and the emotional relationship between aid worker and aid recipient. Emotion has not been absent from aid work. An empathetic relationship is assumed within the symbolism of the humanitarian act itself as well as the personal interactions between aid worker and recipient.

The altruistic ideals of humanitarianism accord with the contemporary therapeutic ethos of donor countries. Empathy has come to the fore as the foundation of ethical behaviour in Western societies, because of their lack of cohering values with the demise of traditional value systems and ideologically-based politics. Humanitarian organisations have become important voices in public discourse following the end of the Cold War. However, the decline of shared ideological, moral or religious convictions in donor states as 'post-traditional' societies has impacted on the convictions of the humanitarian sector. As Vaux vividly testifies in his account of relief work, 'Altruism is a difficult feeling to maintain and a shaky concept in a postmodern world, without given beliefs and morality' (Vaux, 2001, p. 1). 
Humanitarian organisations went through much soul-searching over their mission and their motives in the 1990s, despite the huge expansion in their work and public profile. Indeed the very sponsorship of humanitarian activities by donor governments became a source of anxiety for humanitarian organisations over the way that aid and their role as humanitarians were being politicised. Humanitarians could no longer assume that their role was ethical and benefited recipients: both the nature and the work of humanitarian organisations were fundamentally questioned. Numerous books on humanitarianism have been published over the last decade whose very titles demonstrate how vehemently aid work has been attacked. Michael Maren's The Road to Hell (1997), Timothy Morris' The Despairing Developer (1991), David Sogge's Compassion and Calculation (1996) and Alex de Waal's Famine Crimes (1997) are a just few of the damning critiques that came out in the last decade. Newspapers and magazines too carried negative articles on aid work such as The Economist's 'Sins of the Secular Missionaries' (2000). Even popular culture, normally very positive about humanitarian organisations, portrayed negative images. The cartoon Southpark, for example, satirised humanitarian intervention in its Stavin' Marvin sketch which depicts humanitarianism as a bloated and parasitic industry disrupting the lives of its supposed beneficiaries.

Humanitarian organisations were encouraged to adopt psychosocial work by the crisis of legitimacy. There were three areas of contention: humanitarian principles, the technologies of aid and the efficacy of material aid. The technologies of aid left many aid workers concerned about the bureaucratisation of aid work as its role expanded. Instead of representing an act of empathy between people, there was disquiet that the humanitarian sector was becoming a self-serving industry (Maren, 1997). The sense of humanitarianism becoming alienating rather than humanising was heightened by doubts over the efficacy of humanitarian aid work. Soul-searching led to a questioning of the aid worker and recipient relationship too. Empathy for the person in need appeared no longer to be sufficient to guide interventions, and the motives of aid workers themselves came under scrutiny.

New codes of practice proliferated in the 1990s, but their very elaboration suggested the depth of the crisis in humanitarianism. Definitive principles to guide action remained elusive. The detailed codes multiplied, revealing profound doubts over the ethics of aid work and the integrity of aid workers. Humanitarianism was not only attacked as shorttermist and ineffective in providing for people's needs. Humanitarianism was attacked for actually harming people's welfare. Critiques such as Mary Anderson's Do No Harm (1999), Joanna Macrae's Aiding Recovery? (2001) or Alex de Waal's Famine Crimes (1997) set out how humanitarian aid could exacerbate crises and undermine local economies. The giving of humanitarian aid was problematised for 'feeding the killers' and fuelling conflicts. In war economies, it was found that, 'Any kind of external assistance [...] could be converted into guns; it therefore became impossible to separate humanitarian aid from the war itself' (Vaux, 2001, p. 82). In future, aid was to be judged by how it contributed to resolution of crises and promoted developmental and human rights goals. However, the elusiveness of these goals in the face of recurring disasters and protracted conflicts, and the profound doubts over the principles and consequences of aid 
work all contributed to a demoralised humanitarianism and a demoralised humanitarian aid worker.

One of the attractions of psychosocial work for aid workers has been to bring back the human in the face of the bureaucratisation of aid, foregrounding how people and communities personally experience disaster or conflict. Western aid workers are simultaneously projecting their personal sense of vulnerability and loss of meaning onto disaster or war-affected populations. A sense of purpose mediates distressful situations and encourages difficulties to be interpreted as worthwhile sacrifices (Bracken, 2002; Cherniss, 1995; Frankl, 1964). One study that has looked at the reasons for positive outcomes highlights how:

"Those who view themselves as in charge of their fate (control), who are committed to meaningful goals and activities (commitment), and who view stress as a surmountable challenge are more likely in the long run to integrate the trauma into their lives and to enjoy a satisfactory level of adjustment" (Waysman, 2001, p. 545).

These findings help to explain how aid workers have previously appeared remarkably resilient rather than vulnerable. In the 1970s and 1980s' era of the individual in humanitarianism, aid workers had great autonomy over their activities and great confidence in the rightness of what they were doing. However, for many aid workers, the commitment that comes from meaningful work and fosters resilience has been undermined by the fundamental doubts over their mission and motives. In addition, the thrill of danger and the adrenalin of action in relief work are becoming taboo under the therapeutic ethos alluded to in the previous section. Aid workers are culturally encouraged to be emotionally vulnerable as a sign of caring. Whereas previous generations of aid workers could be buoyed up by their mission, aid workers over the last decade have found themselves exposed not just to distress and danger, but to severe censure and profound misgivings over their relief and developmental activities.

As a disorder of meaning (Bracken, 2002, p. 187), the rise of PTSD among humanitarian staff may be regarded as an exaggerated form of the wider crisis of purpose in humanitarianism. The significance of meaning has been neglected in the literature on PTSD in international relief and development personnel. The literature tends to focus on the severity of exposure to stress and organisational training and support systems for aid workers (Eriksson et al, 2001; McCall and Salama, 1999; Smith et al, 1996). It has been argued that, 'Relief workers today are faced with situations which generate more stress than straightforward natural disasters' (Salama, 1999, p. 12), as if the disasters of the past were straightforward. More straightforward previously, however, was how humanitarians regarded their mission and what ethical dilemmas they set themselves. The humanitarian emergencies of the past were potentially as complex as today, but the Cold War solidarist framework simplified humanitarian responses. In essence, this framework assumed the legitimacy of host governments and aid agencies in humanitarian emergencies, and did not challenge official representations of the crisis, leaving questions of political responsibility and the political role of aid unexplored. The Ethiopian famine of 1984, for example, was never a straightforward famine, but aid agencies responded as if it were 
(Vaux, 2001). The image of a simple natural disaster contrasts with the way that crises are approached today as 'complex political emergencies' such as the current food shortages in Zimbabwe. The idea of the complexity of emergencies and how aid may prolong crises has raised new difficult dilemmas for humanitarian organisations.

The problematising of the humanitarian role in crises, rather than the suffering on the ground, has contributed most to rising mental health problems among aid staff. Mental breakdown among relief workers has strikingly been when they have been most demoralised by their mission. The Somalia mission of 1992 sharply exposed this crisis of morale. Oxfam staff, for example, experienced significant stress problems arising from the mission, which did not simply relate to the suffering and dangers they encountered, but the organisation's ill-prepared responses. An internal evaluation written two years after the mission found that:

"The majority of people spoken to who worked in Somaliland and Somalia were still experiencing distress and trauma as a result of their experience. The feelings varied from nightmares, a loss of confidence, a feeling of failure and dissatisfaction with the work achieved, and feelings of personal inadequacy to anger and disillusion with aid work" (quoted in Vaux, 2001, p. 154).

Rapid growth in trauma counselling for international aid workers, peacekeepers, journalists and human rights workers has accompanied the rise of international trauma counselling. Counselling, however culturally popular, is no solution to a wider crisis of meaning.

Furthermore, psychosocial intervention may be extending alienating technologies through its instrumentalisation of the emotions. The significance of international psychosocial work goes beyond the alleviation of distress. Psychosocial work is being given prominence because of how social problems are being reinterpreted in Western societies as issues of emotional functionalism/dysfunctionalism. Distressful experiences are regarded as triggering traumatic symptoms causing dysfunctionalism leading to cycles of trauma and violence. Acting upon the emotions and promoting a sense of emotional wellbeing are regarded as addressing both the consequences and the causes of crisis by breaking cycles of psychosocial dysfunctionalism. As one international NGO worker involved in trauma counselling in Burundi explains:

"When we look at the cycle of violence, we can see that unless there is healing, mourning and unless you go through the four or five stages of the healing process, you can't reach that area of acceptance. Then the cycle of violence continues" (IRIN, 2002).

Thus trauma is regarded as significant for not only impairing the development and mental wellbeing of the individual, but the future development and wellbeing of the society as a whole. Consequently, the emotions of crisis-affected populations have become a legitimate sphere of external activity, and therapeutic interventions are being burdened 
with broad social tasks. The next section explores the pathologising of war and why psychosocial programmes have become so popular among donors.

\section{Understanding war through a therapeutic model}

The new international humanitarian framework treats violent conflict as a manifestation of psychosocial dysfunctionalism. This pathologising of war relates to the outlook of contemporary Western society. Lacking strong convictions themselves, donor countries find it difficult to imagine people believing in causes they consider worth fighting for and project populations at war as dysfunctional. War is almost invariably discussed as having a negative impact on a population's mental health. Current understanding assumes universal vulnerability, whereas earlier models assumed the general resilience of people. International reports typically speak of war causing a 'vicious circle' of 'psychosocial dysfunction, new instability, new vulnerabilities, and new hazards' (WHO, 2002, p. 6). Thus international psychosocial programmes seek to address 'unresolved communal psychological wounds' as 'one of the most - if not the most - powerful fuels of future war and violent conflicts' (Common Bond Institute, 2003) and as shaping 'future political/ideological development and/or decision-making' (Volkan, 2001).

There are now thousands of international projects providing trauma therapy for war victims. However, projections of mass trauma are not borne out in practice. The lack of spontaneous identification with trauma in non-Western societies has been striking. A practical 'problem focused coping style' is common to non-Western societies as compared with the 'emotion focused coping style' of contemporary Western therapeutic cultures (Summerfield, 2001). Problems are not automatically conceptualised in therapeutic terms even where survivors experience distressing reactions such as nightmares (ibid.). Aid agencies acknowledge encountering few individuals who would classify themselves as suffering from a psychological disorder (Wiles et al, 2000). International aid workers, predominantly Westerners, are actually far more likely to identify themselves as having PTSD than the war-affected population itself. However, the precautionary principle of contemporary risk consciousness decrees that policy should be formulated on the basis of the potential for a disorder developing. Yet the effectiveness of trauma counselling is contested. The current advice of the Cochrane Review is that, 'There is no current evidence that psychological debriefing is a useful treatment for the prevention of post traumatic stress disorder after traumatic incidents' (Rose et al, 2003). Indeed many refugees experience the provision of trauma counselling as stigmatising (Wiles et al, 2000). Greatly appreciated in emergency situations, instead, are the message and tracing services along with the practical assistance and any personal instances of friendliness, kindness, or consideration by individual aid workers that recognise them as fellow human beings. But ultimately psychological recovery comes from the overall circumstances and meaning of people's lives and not simply from what is inside people's heads as the international therapeutic model implies, as Summerfield discusses in this volume and elsewhere (2002).

The situation of the post-Yugoslav states is interesting for some of the social developments that have encouraged the therapeutic turn in the United States and Western Europe apply to Central and East European states. Given the aspirations of the new states 
for inclusion in the European Union, there is a keenness to identify with Western trends, including Western therapeutic sensibilities. Thus critiques on the inappropriateness of Western therapeutic approaches for non-Western societies are resisted as implicitly undermining their claims to a Western identity and inclusion in Western intergovernmental organisations. The attractiveness of PTSD is very apparent in Croatia with thousands of veterans queuing up for the diagnosis and war pensions based on their psychological state. With 80 percent of war pension claims on the basis of PTSD, Croatia illustrates the dangers of the current therapeutic model and the validation of vulnerability. For the government's responses have perversely given incentives to individuals to adopt a sick role rather than promote recovery: war pensions have actually been set at higher levels than key public sector salaries. Unsurprisingly, instead of the numbers of veterans diagnosed with PTSD declining since the end of the war eight years ago, the numbers continue to escalate. 10,000 are now registered and the Minister for Croatian Veterans is predicting that it may rise to as many as 80,000 (Hauswitschka, 2003). Yet tellingly there is an absence of PTSD diagnosis among veterans registered as 100 percent disabled: they are presumably already entitled to a war pension without requiring the diagnosis. The government is now faced with financial crisis arising from its readiness to recognise PTSD among its war veterans: war pensions represent a significant drain on the government's budget.

In highlighting the dangers of validating vulnerability, this is not to deny issues of emotional ill-being - the suicide rate in Croatia is reportedly higher than after the Second World War and is comparable to the numbers killed in the war (Dujic, 2002). Nevertheless, emotional ill-being in the country cannot simply be treated as a mental health issue, but is bound up with the disappointments of the peace which has not yet brought economic prosperity and integration into the European Union. The therapeutic model is inadequate to address a generalised lack of purposefulness in society. Moreover, the call for therapeutic interventions as 'preventive medicine' (Volkan, 2001) even where populations appear resilient may perpetuate emotional problems by denying populations' own coping strategies and creating unaccountable relations of dependency. As the salutogenic study cited above highlights those who view themselves as in charge of their fate are more likely to have positive outcomes (Waysman et al, 2001). Yet against this finding, the new post-conflict strategies imply extensive loss of local control under comprehensive external governance, as has been the case in Bosnia (Pupavac, 2004 forthcoming). The humiliation of dependency on the international community has been identified as affecting the population's emotional well-being (de Jong et al, 1999). Longitudinal studies of trauma in war-affected populations under de facto international protectorates need to take into account such suspension of self-determination in analysing mental health. The trauma label is rightly experienced by many societies as stigmatising for it is being invoked to deny their capacity more generally, with implications for their rights and freedoms.

\section{Re-moralising resilience}

The present casual reference to war-affected populations as traumatised is unhelpful in formulating appropriate responses. The predominant international trauma approach 
validates vulnerability and casts doubt on resilience. The demoralising of resilience under contemporary culture has been neglected until recently. The importance of fostering resilience was brought home to policy-makers following the terrorist attack on the World Trade Centre. An anxious ethos cultivating emotional vulnerability is distinctly illequipped to manage terrorist threats whose very tactic is to promote fear. Policy needs to tackle how people are inhibited from being resilient because of the prevailing cultural norms. Researchers at the International Policy Institute of the War Studies Group at King's College London have suggested 'the need for an approach that clarifies people's values rather than emphasising their vulnerabilities' (Durodie and Wessely, 2002). This recommendation is useful in identifying how a generalised lack of meaning in society contributes to emotional vulnerability.

An age of relativism does not generate strong belief systems that promoted people of character in the past. The clarification of values may remain elusive for the foreseeable future in the humanitarian sector as more generally in Western societies. However, this crisis of meaning and its manifestation in emotional vulnerability is not universal. There is a danger that international psychosocial programmes become a global education into vulnerability. Therapeutic approaches, focused on feelings rather than activities, may encourage adoption of sick roles, fostering social disengagement and isolation as in Croatia. A starting point for national and international policy should be the remoralisation of resilience. Individuals or communities who demonstrate hardiness and do not seek counselling should not be pathologised as being 'in denial' of their 'hidden scars'. It should be remembered that adverse experiences may promote resilience and galvanise dormant communal responsiveness (Joseph et al, 1993). There is new interest in findings of resilience (Rogers, 2003). A study of the reconstitution of New York City's Emergency Operations Centre, for example, found elements of resilience and that this resilience was extremely important for the efficacy of the emergency services' responses (Kendra and Wachtendorf, 2003). In this spirit, a New York community reconstruction project has named itself NYC Recovers (see Fullilove et al in this volume). Even where value systems are weak, resilience may be supported by affirming people's professional values: their skills, activities and courage as firefighters or water engineers and so on. But it should also be warned that a resilience paradigm is being taken up in official policies in ways which re-create the assumptions of the earlier vulnerability paradigm and assume that people cannot be resilient without expert interventions.

The lessons of resilience are vital for addressing the reconstruction of disaster and waraffected communities internationally as well as the domestic management of the new security threats faced by Western societies. The casual projection of populations as traumatised and dysfunctional under international psychosocial programmes is experienced as stigmatising. Humanitarian organisations need to rethink how they approach the issue of the emotional well-being of war-affected populations and their own staff. A sense of meaningfulness is crucial to emotional well-being. The demoralisation of the humanitarian mission underlies the rise of PTSD among humanitarian workers and the pathologisation of populations. A mental health model is inadequate and may be inappropriate to address the emotional well-being of both war-affected populations and humanitarian organisations. Moreover the tendency of the international psychosocial 
approach to conflate traumatisation with brutalisation is dehumanising and unethical. At the heart of the humanitarian mission and modern ethics has been the belief in fellow human beings. Affirmation of this core principle of humanity is vital to the morale and morality of humanitarianism and the wider search for meaning.

\section{References}

Anderson, M. (1999) Do No Harm: How Aid Can Support Peace - or War. Boulder, CO: Lynne Rienner.

Bracken, P. (2002) Trauma: Cultural Meaning and Philosophy. Whurr Publishers, London.

Cherniss, C. (1995) Beyond Burnout: Helping Teachers, Nurses, Therapists, and Lawyers Recovery from Stress and Disillusionment. Routledge, New York and London.

Common Bond Institute (2003) $11^{\text {th }}$ Annual International Conference on Conflict Resolution http://www.aphweb.org, accessed 24 March 2003.

Coward, R. (2001) Seeing is Reliving. Observer, 4 March.

Eriksson, C., Kemp, H., Gorsuch, R., Hoke S. \& Foy D. (2001) Trauma Exposure and PTSD Symptoms in International Relief and Development Personnel. Journal of Traumatic Stress, 14(1), 205-212.

Dart Center for Journalism and Trauma http://www.dartcenter.org

Durodie, B. \& Wessely, S. (2002) Resilience or panic? The public and terrorist attack. The Lancet, 360, 14 December.

Dujic, G. (2002) Je li patnja hrvatskih branitelja imala smisla? [Did the suffering of Croatian veterans serve any purpose?] Hrvatsko Slovo, 26 April. http://www.hkz.hr/Hrvatsko_slovo/2002/366/t112.htm

The Economist (2000) Sins of the Secular Missionaries. 29 January, 25-28.

Frankl, V. E. (1964) Man's Search for Meaning: An introduction to logotherapy. Hodder and Stoughton, London.

Furedi, F. (2002a) Drug Control and the Ascendancy of Britain's Therapeutic Culture. In: Drug Courts in Theory and in Practice. Edited by J. Nolan. Aldine de Gruyter, Hawthorne, NY, 251-234.

Furedi, F. (2002b) The Institutionalisation of Recognition - Evaluating the Moral Stalemate. Paper presented to DMAP Conference, University of Cardiff, 4-6 April. 
Giddens, A. (1994) Beyond Left and Right: The Future of Radical Politics. Polity Press, Cambridge.

Hauswitschka, A. (2003) Pancic: Od PTSP-a je napravljen bauk. Vjesnik, 16 April. http://www.vjesnik.hr/html

IRIN (2002) Burundi: Focus on trauma healing. 10 September. http://www/irinnews.org

De Jong, K. Ford, N. \& Rolf Kleber (1999) Mental health care for refugees from Kosovo: the experience of Medecins Sans Frontieres. The Lancet, 353, 8 May, 1616-1617.

Joseph, S., Williams, R. \& Yule, W. (1993) Changes in outlook following disaster: The preliminary development of a measure to assess positive and negative responses. Journal of Traumatic Stress, 6, 271-279.

Kendra, J. \& Wachtendorf, T. (2003) Elements of Resilience: After the World Trade Center Disaster: Reconstituting New York City's Emergency Operations Centre. Disasters, 27(1), 37-53.

Lasch, C. (1984) The Minimal Self: Psychic Survival in Troubled Times. W.W. Norton, New York.

Macrae, J. (2001) Aiding Recovery? The Crisis of Aid in Chronic Political Emergencies. Zed Books, London.

Mayes, T. (2000) Submerging in Therapy News. British Journalism Review, 11(4), 3036.

Maren, M. (1997) Road to Hell. Free Press, New York.

McCall, M. \& Salama, P. (1999) Selection, training, and support of relief workers: an occupational health issue. British Medical Journal, 318, 9 January, 113-116.

Mestrovic, S. (1997) Postemotional Society. Sage, London.

Mollica, R. (2000) A Society at War from Invisible Wounds. Scientific American, June, 54-57.

Morris, T. (1991) The Despairing Developer: Diary of an Aid Worker. I.B. Taurus, London.

Nolan, J. (1998) The Therapeutic State: New York: Justifying Government at Century's End. New York University Press, New York.

Pupavac, V. (2004, forthcoming) The Emotionology of the New International Security Paradigm. European Journal of Social Theory, 7(4), February. 
Rogers, L. (2003) How tragedy changed lives for the better. The Sunday Times, 16 March, 14.

Rose S., Bisson, J. \& Wessely, S. (2003) Psychological debriefing for preventing post traumatic stress disorder (PTSD) (Cochrane Review). In The Cochrane Library Issue 2. Update Software, Oxford.

Salama, P. (1999) The Psychological Health of Relief Workers: Some Practical Suggestions. Relief and Rehabilitation Network, 15, 12-14.

Samuels, A. (2001) Politics on the Couch: Citizenship and the Internal Life. Profile Books, London.

Sennett, R. (1998) The Corrosion of Character: The Personal Consequences of Work in the New Capitalism. W.W. Norton, New York.

Shaw, I. \& Middleton, H. (2001) Recognising Depression in Primary Care. The Journal of Primary Care Mental Health, 5(2), 24-27.

Smith, B, Agger, I., Danieli, Y. \& Weisaeth, L. (1996) Health activities across traumatized populations: Emotional responses of international humanitarian aid workers. In International Responses to Traumatic Stress. Edited by Y. Danieli, N. Rodley \& L. Weisaeth. Baywood Publishing, Amityville, NY, 397-423.

Sogge, D. (ed.) (1996) Compassion and Calculation: The Business of Private Foreign Aid. Pluto, London.

Summerfield, D. (2001) 'The Invention of Post-Traumatic Stress Disorder and the Social Usefulness of a Psychiatric Category.' British Medical Journal, 322, 95-98.

Summerfield, D. (2002) The Effects of War: Moral Knowledge, Revenge, Reconciliation and "Recovery." British Medical Journal, 325, 1105-1107.

Volkan, V. (2001) Traumatized Societies and Psychological Care: Expanding the Concept of Preventive Medicine. Mind and Human Interaction. 11 (3), 177-194. http://www.healthsystem.virginia.edu/internet/csmhi/volkan.cfm

Vaux, T. (2001) The Selfish Altrusist: Relief Work in Famine and War. Earthscan, London.

De Waal, A. (1997) Famine Crimes: Politics and the Disaster Relief Industry in Africa. James Currey, Oxford.

Waysman, M., Schwarzwald, J. \& Solomon, Z. (2001) Hardiness: An Examination of its Relationship with Positive and Negative Long Term Changes following Trauma. Journal 
of Traumatic Stress, 14(3), 531-548.

WHO (2002) Breaking the Vicious Circle. Health in Emergencies, March, 12, p. 6.

Wiles, P. et al (2000) Independent Evaluation of Expenditure of DEC Kosovo Appeal Funds. Phases I and II, April 1999-January 2000. Volume II. ODI with Valid International. ODI, London. 